\title{
Impact of emotional intelligence and flexibility on the tendency of employees to leave the organ- ization in project based organizations
}

\author{
Hossein Mohammadi and Yousef Abbasi*
}

Department of Commerce and Marketing, Zanjan Branch, Islamic Azad University, Zanjan, Iran

\section{H R O N I C L E}

Article history:

Received: March 5, 2017

Received in revised format: July

16,2017

Accepted: August 2, 2017

Available online:

August 5, 2017

Keywords:

Project based organization

Emotional intelligence

Flexibility

\section{A B S T R A C T}

\begin{abstract}
Sentiment is a powerful psychological force that can significantly affect employee behavior and performance. However, workplace emotions are still an issue to be studied, especially in the field of sales management in project based organizations. The purpose of this study is to investigate the effect of emotional intelligence and flexibility on the tendency of employees to leave the organization. The method of this research is descriptive correlational and in a survey method and it is a practical purpose. The statistical population of this study includes all 108 employees of the representatives of selected insurance firms in city of Zanjan, Iran. Using Cochran formula, 84 people were selected as the statistical sample. The results have indicated that while there was a positive and meaningful relationship between emotional intelligence and flexibility $(r=0.534$, Sig. $=0.000)$, there were negative and meaningful relationships between flexibility and emotional intelligence on one side and intend to leave an organization on the other side.
\end{abstract}

\section{Introduction}

Understanding the effects of employee benefits on how an organization can attract and retain capable employees plays important role for the success of any firm. Benefits make the organization an attractive place to work and can motivate employees to stay (Cotton \& Tuttle, 1986). Recognizing and retaining human resources is not just keeping people in the organization, but creating a good motivation for them to enjoy working within organization (Meyer, 1993). A loyal human being who is consistent with organizational goals and values and is willing to work beyond the duties specified in the job descriptions can be considered as a valuable asset for any firm (Larson \& Lakin, 1999). The presence of such a force in any organization not only increases the level of performance and reduces the rate of absenteeism, delay and quitting, but it also manifests the reputation of the organization in the community and provides the ground for its growth and development (Mitchell \& Braddock, 1994). In fact, human resources are one of the most important resources of the organization to achieve the goals. Therefore, organizations are looking for appropriate programs to attract and maintain effective human resources. Various

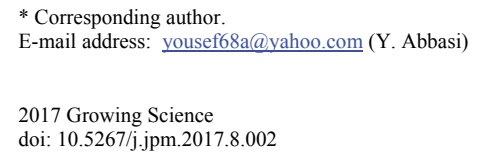


factors play a role in the effectiveness of human resources, and researchers are looking to examine these factors and their impacts on human resource performance (Moorman, 1991).

In other words, in order to increase productivity, improve and increase the quality of service delivery, increase the level of employee motivation and employees' greater interest in their duties, managers should do their best to keep their employees in organization (Daileyl \& Kirk, 1992). Therefore, identifying the factors affecting them in the organization positively and thereby increasing the level of these variables among the organization's individuals play important role for the sustainability of an organization. In this regard, many studies have been carried out in various organizations to identify the factors affecting the staff to leave organizations. In the meantime, most of these studies have emphasized the cognitive aspects of employee performance and fewer works studied the relationship between the emotional dimensions and the flexibility of the staff (Hatton \& Emerson, 1993). Emotional intelligence (Goleman, 1998; Cherniss, 2000) is a skill that its owner can control through self-awareness, self-control, self-management, through empathy. In addition, flexibility is also vital for a healthy lifestyle (Cheng, 2003). Flexibility is often used in social interactions and membership in associations and centers. It also helps project based organizations. In a project-based organizational structure, employees are assigned to projects and report to the project manager. The project manager performs performance appraisals and prepares career development plans for project team members. This increases employee loyalty to project objectives. In addition, since the project manager has direct control and authority over project operations, flexibility and response time for changing circumstances improve.

Berg (1991) determined the possible issues, which could predict employee intent to stay at commercial television stations. In this survey, employees of five commercial television stations completed a questionnaire, which concentrated on employee turnover in three departments; namely news, production, and sales. According to Berg (1991) "a category of system outcomes could predict perception of equity; that a category of interpersonal outcomes, in conjunction with opportunity and perception of equity, predicted job satisfaction; and that job satisfaction, in conjunction with perception of equity and education, predicted intent to stay". Blau and Boal (1989) reported that an interaction of job involvement and organizational commitment could account for significant turnover variance beyond demographic variables, job withdrawal cognitions, and the job involvement and organizational commitment main effects. Kidwell and Valentine (2009) reported that that employees perceptions of positive group context play an essential role in the presence of misbehavior at work. They also reported that positive group context could be a vital element of ethical climate, which ought to be managed to temper occurrence of such adverse work behavior. Kim et al. (1996) explained variation in career intent among physicians at a U.S. Air Force hospital using a causal model to explain career intent. The causal model tested primarily for female employees in civilian hospitals was detected to operate just as well among male physicians in a military hospital. Koh and Goh (1995) investigated the factors influencing on turnover intention to build a turnover prediction model. The results indicated that demographic and job attitude factors were not substantially associated with turnover intention. On the contrary, job satisfaction factors influenced on turnover intention positively. More specifically, satisfaction with career future, company identity, kind of work and financial rewards were determined to be significant.

Rezvani et al. (2016) examined a model linking emotional intelligence (EI) to project success and examine the mediating effects of project managers' job satisfaction and trust on this relationship. They reported that EI had a positive effect on project success, job satisfaction, and trust. Moreover, they reported some evidence that job satisfaction and trust could mediate the relationship between EI and project success. The findings imply that top management could be aware of the importance of project managers' job satisfaction and trust, which could both serve to boost project success in complex project situations. Xiang et al. (2016) reported that shared mental model could enhance the effects of EI on project team performance. Clarke (2010) investigated the effect of a training programs designed to target EI abilities of project managers. They reported that training could have an effect on the project managers' EI but that other conditions following attendance on training could also be necessary. 


\section{The proposed study}

The purpose of this study was to investigate the effect of emotional intelligence and flexibility on the tendency of employees to leave the organization. The method of this research is descriptive correlational and in a survey method and it is a practical purpose. There are three hypotheses associated with the proposed study of this paper as follows,

1. Employees' EI has a positive impact on their flexibility.

2. Employees' flexibility has a negative impact on leaving the organization.

3. Employees' EI has an impact on leaving the organization.

Fig. 1 shows the structure of the proposed study. In order to determine the sample size we use Eq. (1) as follows,

$$
n=\frac{N \times z_{\alpha / 2}^{2} \times p \times q}{\varepsilon^{2} \times(N-1)+z_{\alpha / 2}^{2} \times p \times q},
$$

where $N$ is the population size, $p=1-q$ represents the yes/no categories, $z_{\alpha / 2}$ is CDF of normal distribution and finally $\varepsilon$ is the error term. Since we have $p=0.5, z_{\alpha / 2}=1.96$ and $N=108$, the number of sample size is calculated as $n=84$.

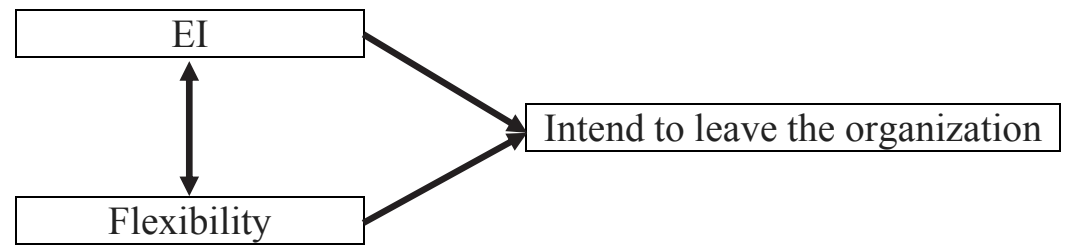

Fig. 1. The structure of the proposed study

The statistical population of this study includes all 108 employees of the representatives of selected companies of insurance in city of Zanjan, Iran. Using Cochran formula, 84 people were selected as the statistical sample. The study was conducted among the employees of four insurance firms and the sample size was determined as shown in Table 2 as follows,

\section{Table 2}

The summary of sample size

\begin{tabular}{clcc}
\hline Row & Name & Number of employees & Sample size \\
\hline 1 & Karafarin & 38 & 31 \\
2 & Pasargad & 35 & 28 \\
3 & Parsian & 19 & 14 \\
4 & Sina & 16 & 11 \\
\hline Total & & 108 & 84 \\
\hline
\end{tabular}

The study designed a questionnaire, which consists of several questions associated with each part of the survey and details are summarized in Table 3 as follows,

\section{Table 3}

The summary of the number of questions used in the survey

\begin{tabular}{lll}
\hline Variable & Number of questions & Cronbach alpha \\
\hline Emotional intelligence & 28 & 0.933 \\
Self-awareness & 6 & 0.893 \\
Self-assessment & 9 & 0.920 \\
Social-awareness & 5 & 0.953 \\
Relationship management & 8 & 0.968 \\
Flexibility & 11 & 0.821 \\
Intend to leave & 9 & 0.761 \\
\hline
\end{tabular}


As we can observe from the results of Table 3, all components have maintained a high level of Cronbach alphas, which confirm the overall questionnaire. In our survey, $60.7 \%$ of the participants were male and the $39.3 \%$ of them were female. Moreover, over $70 \%$ of them have maintained at least 5 years of job experience. Fig. 2 demonstrates other personal characteristics of the participants.

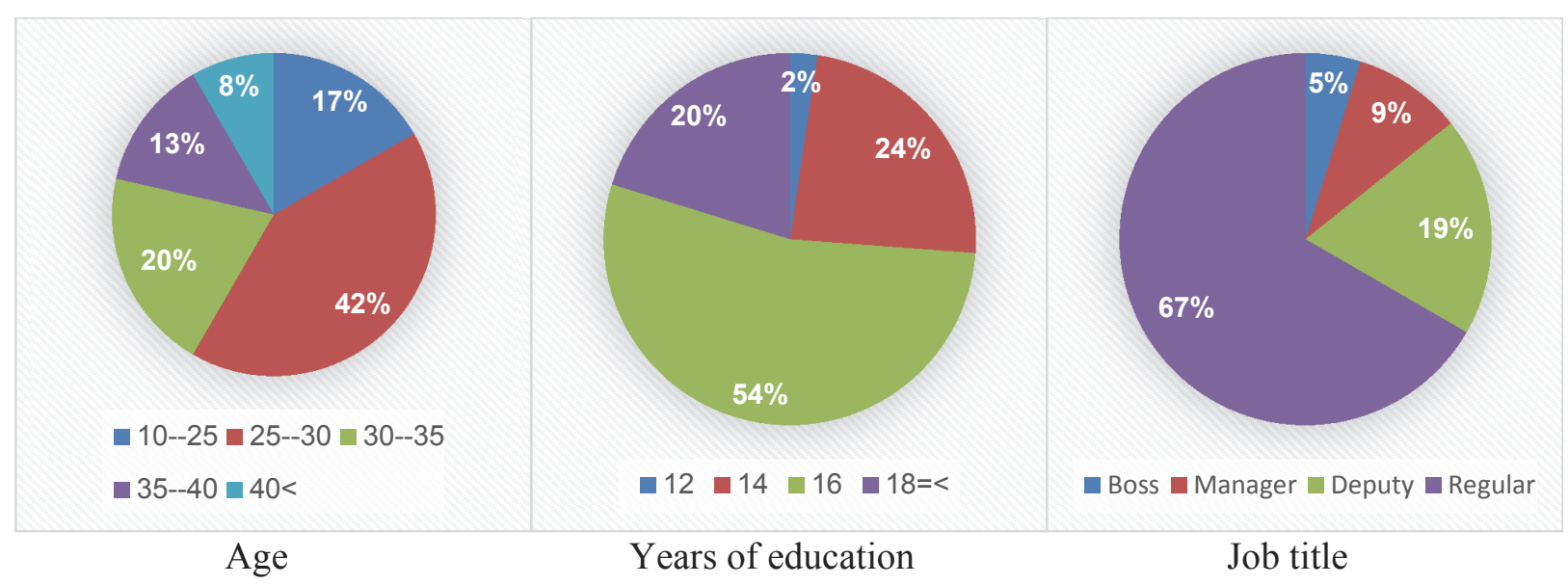

Fig. 2. Personal characteristics of the participants

In order to examine the hypotheses of the paper, we first examine the normality of components using Kolmogorov-Smirnov (KS) test. Table 4 shows the results of our survey. As we can observe from the results of Table 4 , all three variables are normally distributed.

\section{Table 4}

The summary of Kolmogorov-Smirnov test

\begin{tabular}{lccc}
\hline Variable & Sample & KS & Sig. \\
\hline Leaving the organization & 84 & 2.233 & 0.063 \\
Emotional intelligence & 84 & 0.721 & 0.341 \\
Flexibility & 84 & 1.512 & 0.635 \\
\hline
\end{tabular}

\section{The results}

In this section, we present details of the implementation of Pearson correlation and regression analysis to test the three hypotheses of the survey.

\subsection{The first hypothesis: relationship between EI and flexibility}

The first hypothesis of the survey examines the relationship between EI and flexibility. The implementation of Pearson correlation between these two variables yields $r=0.534$ with Sig. $=0.000$, which means there was a positive and meaningful relationship between these two variables and therefore, the first hypothesis of the survey has been confirmed. In addition, Table 5 demonstrates the results of regression analysis.

\section{Table 5}

The summary of regression test between EI and flexibility

\begin{tabular}{lccccc}
\hline & \multicolumn{2}{c}{ Non-standard coefficient } & Standard coefficient & t-value \\
\cline { 2 - 6 } & Beta & Standard dev. & & & \\
\hline Intercept & 11.231 & 2.535 & & 4.431 & 0.000 \\
Slope & 0.48 & 0.066 & 0.534 & 7.272 & 0.000 \\
\hline
\end{tabular}


The results of Table 5 also confirm the positive relationship between these two components.

\subsection{The second hypothesis: relationship between flexibility and leaving the organization}

The second hypothesis of the survey investigates the relationship between leaving the organization and flexibility. The implementation of Pearson correlation between these two variables yields $r=-0.712$ with Sig. $=0.000$, which means there was a negative and meaningful relationship between these two variables and therefore, the second hypothesis of the survey has been confirmed. In addition, Table 6 demonstrates the results of regression analysis.

\section{Table 6}

The summary of regression test between flexibility and leaving the organization

\begin{tabular}{lccccc}
\hline & \multicolumn{2}{c}{ Non-standard coefficient } & Standard coefficient & t-value \\
\cline { 2 - 6 } & Beta & Standard dev. & & & \\
\hline Intercept & 1.514 & 2.089 & & 0.724 & 0.000 \\
Slope & -0.685 & 0.054 & -0.712 & 12.595 & 0.000 \\
\hline
\end{tabular}

The results of Table 6 also confirm the negative effect of employee's flexibility on leaving the organization.

\subsection{The third hypothesis: relationship between EI and leaving the organization}

The third hypothesis of the survey studies the relationship between leaving the organization and emotional intelligence. The implementation of Pearson correlation between these two variables yields $r=-$ 0.853 with Sig. $=0.002$, which means there was a negative and meaningful relationship between these two variables and therefore, the third hypothesis of the survey has been confirmed. In addition, Table 7 demonstrates the results of regression analysis.

Table 7

The summary of regression test between EI and leaving the organization

\begin{tabular}{lccccc}
\hline & \multicolumn{2}{c}{ Non-standard coefficient } & Standard coefficient & t-value & \\
\cline { 2 - 6 } & Beta & Standard dev. & & & \\
\hline Intercept & 24.583 & 1.979 & & 14.420 & 0.000 \\
Slope & -1.019 & 0.041 & -0.853 & 24.858 & 0.000 \\
\hline
\end{tabular}

The results of Table 7 also confirm the negative effect of employee's emotional intelligence on leaving the organization.

\section{Conclusion}

In this paper, we have presented an empirical investigation to study the relationship between flexibility, emotional intelligence and intend to leave an organization in project based organizations. The proposed study designed a questionnaire in Likert scale and distributed it among some firms in insurance industry. The results have indicated that while there was a positive and meaningful relationship between emotional intelligence and flexibility, there were negative and meaningful relationships between flexibility and emotional intelligence on one side and intend to leave an organization on the other side. Flexibility is one of the components of emotional intelligence, which helps individuals adapt the employees' capabilities to conditions that are unfamiliar, unpredictable, and dynamic. Flexible people are able to change their minds when there are evidences, which indicate that they were wrong. Flexible people are often characterized by attributes such as consistent, savvy, open and tolerant to differences. Flexible people are not fanatics and they do not always insist that they are right. People who are very flexible 
may seem like people who risk their own principles to welcome power. In this situation, it can no longer be considered an instrument of emotional intelligence.

\section{References}

Berg, T. R. (1991). The importance of equity perception and job satisfaction in predicting employee intent to stay at television stations. Group \& Organization Studies, 16(3), 268-284.

Blau, G., \& Boal, K. (1989). Using job involvement and organizational commitment interactively to predict turnover. Journal of management, 15(1), 115-127.

Cherniss, C. (2000, April). Emotional intelligence: What it is and why it matters. In annual meeting of the Society for Industrial and Organizational Psychology, New Orleans, LA (Vol. 15).

Cheng, C. (2003). Cognitive and motivational processes underlying coping flexibility: A dual-process model. Journal of personality and social psychology, 84(2), 425.

Clarke, N. (2010). The impact of a training programme designed to target the emotional intelligence abilities of project managers. International Journal of Project Management, 28(5), 461-468.

Cotton, J. L., \& Tuttle, J. M. (1986). Employee turnover: A meta-analysis and review with implications for research. Academy of management Review, 11(1), 55-70.

Daileyl, R. C., \& Kirk, D. J. (1992). Distributive and procedural justice as antecedents of job dissatisfaction and intent to turnover. Human Relations, 45(3), 305-317.

Goleman, D. (1998). Working with emotional intelligence. Bantam.

Hatton, C., \& Emerson, E. (1993). Organizational predictors of perceived staff stress, satisfaction, and intended turnover in a service for people with multiple disabilities. Mental retardation, 31(6), 388.

Kidwell, R. E., \& Valentine, S. R. (2009). Positive group context, work attitudes, and organizational misbehavior: The case of withholding job effort. Journal of Business Ethics, 86(1), 15-28.

Kim, S. W., Price, J. L., Mueller, C. W., \& Watson, T. W. (1996). The determinants of career intent among physicians at a US Air Force hospital. Human relations, 49(7), 947-976.

Koh, H. C., \& Goh, C. T. (1995). An analysis of the factors affecting the turnover intention of nonmanagerial clerical staff: A Singapore study. International Journal of Human Resource Management, 6(1), 103-125.

Larson, S. A., \& Lakin, K. C. (1999). Longitudinal study of recruitment and retention in small community homes supporting persons with developmental disabilities. Mental Retardation, 37(4), 267-280.

Meyer, J. P., Allen, N. J., \& Smith, C. A. (1993). Commitment to organizations and occupations: Extension and test of a three-component conceptualization. Journal of applied psychology, 78(4), 538.

Mitchell, D., \& Braddock, D. (1994). Compensation and turnover of direct-care staff in developmental disabilities residential facilities in the United States. Mental Retardation, 32(1), 34.

Moorman, R. H. (1991). Relationship between organizational justice and organizational citizenship behaviors: Do fairness perceptions influence employee citizenship?. Journal of applied psychology, 76(6), 845.

Rezvani, A., Chang, A., Wiewiora, A., Ashkanasy, N. M., Jordan, P. J., \& Zolin, R. (2016). Manager emotional intelligence and project success: The mediating role of job satisfaction and trust. International Journal of Project Management, 34(7), 1112-1122.

Xiang, C., Yang, Z., \& Zhang, L. (2016). Improving IS development teams' performance during requirement analysis in project-The perspectives from shared mental model and emotional intelligence. International Journal of Project Management, 34(7), 1266-1279.

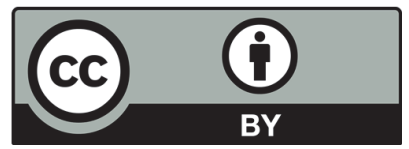

(C) 2017 by the authors; licensee Growing Science, Canada. This is an open access article distributed under the terms and conditions of the Creative Commons Attribution (CC-BY) license (http://creativecommons.org/licenses/by/4.0/). 